•研究报告・

\title{
鼎湖山南亚热带常绿阔叶林林窗 分布格局及其成因
}

\author{
隋丹丹 $1,2,3$ 王 悦 $1,2,3$ 练琚愉 ${ }^{1,2}$ 张 健 ${ }^{4}$ 胡健波 ${ }^{5}$ \\ 欧阳学军 1,2 范宗骥 1,2 曹洪麟 ${ }^{1,2}$ 叶万辉 1,2 \\ 1 (中国科学院华南植物园退化生态系统植被恢复与管理重点实验室, 广州 510650) \\ 2 (中国科学院华南植物园广东省应用植物学重点实验室, 广州 510650) \\ 3 (中国科学院大学, 北京 100049) \\ 4 (华东师范大学生态与环境科学学院, 上海 200241) \\ 5 (交通运输部天津水运工程科学研究所, 天津 300456)
}

\begin{abstract}
摘要: 林窗数量特征及其空间分布格局对南亚热带森林生态系统的动态变化、物种共存及生物多样性的维持等具 有重要意义。本文基于鼎湖山南亚热带常绿榈叶林 20 ha动态监测样地 2015 年的植被调查数据, 结合无人机航拍图 像处理技术和地理信息系统，分析了样地内林窗的几何特征和空间分布格局。结果表明：该样地的林窗空隙率为 $13.72 \%$, 密度为 35.75 个 $/ \mathrm{ha}$, 平均面积 $38.37 \mathrm{~m}^{2}$ 。具体特征有: (1)区域内林窗数量随林窗面积的增加呈负指数分布, 整体表现为小林窗多、大林窗少的规律。(2)不同成熟度林分中, 过熟林林窗平均面积大于成熟林; 成熟林更能体 现出小林窗多而大林窗少的特点。(3)各生境林窗分布与大样地整体表现出基本一致的规律, 但低谷与其他生境差 异显著, 林窗平均面积、林窗空隙率等都大于其他生境, 而山脊林窗也在林窗空隙率与林窗密度方面低于其他生 境。(4)林窗面积和地形因子显著相关: 与海拔和凹凸度呈显著负相关; 与坡度和坡向呈显著正相关。据此提出建 立利用无人机进行森林群落林冠变化与格局的监测体系, 是实现林窗与林下群落动态变化同步监测的新手段。

关键词：常绿阔叶林；林窗密度；林窗面积；林窗空隙率；轻量级无人机
\end{abstract}

\section{Gap distribution patterns in the south subtropical evergreen broad-leaved forest of Dinghushan}

Dandan Sui ${ }^{1,2,3}$, Yue Wang ${ }^{1,2,3}$, Juyu Lian ${ }^{1,2 *}$, Jian Zhang ${ }^{4}$, Jianbo $\mathrm{Hu}^{5}$, Xuejun Ouyang ${ }^{1,2}$, Zongji Fan ${ }^{1,2}$, Honglin $\mathrm{Cao}^{1,2}$, Wanhui $\mathrm{Ye}^{1,2}$

1 Key Laboratory of Vegetation Restoration and Management of Degraded Ecosystems, South China Botanical Garden, Chinese Academy of Sciences, Guangzhou 510650

2 Guangdong Provincial Key Laboratory of Applied Botany, South China Botanical Garden, Chinese Academy of Sciences, Guangzhou 510650

3 University of Chinese Academy of Sciences, Beijing 100049

4 School of Ecological and Environmental Sciences, East China Normal University, Shanghai 200241

5 Tianjin Research Institute of Water Transport Engineering, Ministry of Transport, Tianjin 300456

Abstract: Studying the dynamic characteristics, species coexistence and biodiversity conservation mechanisms of subtropical forest ecosystems is important in the study of the quantitative characteristics and spatial gap distribution patterns. Based on census data from the 20 ha dynamics plot of the subtropical evergreen broad-leaved forest in Dinghushan in 2015, we analyzed the geometric characteristics and spatial distribution pattern of gaps in the plot by combining aerial image processing technology of unmanned aerial vehicles and GIS. Results show that the gap fraction is $13.72 \%$, the gap density is 35.75 no./ha, and the average gap area is $38.37 \mathrm{~m}^{2}$. Results also show that: (1) The number of gaps in the area is negatively exponentially distributed with the increase of gap area, that is, the gap is small and the marginal effect is not significant. (2) The aver-

收稿日期: 2017-02-01; 接受日期: 2017-03-30

基金项目: 国家自然科学基金(41371078,31100312)和中国森林生物多样性监测网络项目

* 通讯作者 Authors for correspondence. E-mail: lianjy@scbg.ac.cn 
age area of forest gaps in over-mature forest stands is larger than that in mature forests, while the mature forest is more likely to have more small gaps and fewer large gaps. (3) In different habitats, the distribution of gaps in each habitat shows the same pattern as that found in the whole plot. However, the difference in the valley is significant when compared with other habitats, and gap area and gap density in the valley are larger than other habitats. The ridge gap is also distinctive, and its gap density is lower than other habitats. (4) Gap area is significantly correlated with topographic factors. It was significantly negatively correlated with altitude and convexity, and had a significantly positive correlation with aspect and gradient. Based on these comparative analyses, a monitoring system of forest canopy changes and patterns can be established using drones, to dynamically monitor forest gaps and the undergrowth community.

Key words: evergreen broad-leaved forest; gap density; gap area; gap fraction; drone

物种多样性及其共存的生态学驱动机制一直 是群落生态学的中心问题(Conell，1978; Huston, 1979; Tokeshi, 1999)。林窗(gap)作为森林的特性之 一, 对于森林群落的物种更新和维持具有重要作用 (Shugart, 1984; Hubbell et al, 1999; 梁晓东和叶万辉, 2001)。林窗是一种中小尺度干扰, 是由林冠层乔木 的死亡或移除等原因造成的林冠层不连续的林中 空隙(Watt, 1947), 是森林生态系统长期变化中必不 可少的要素之一, 对森林更新、结构优化、功能提 高, 特别是应对全球气候变化能力的提高有重要作 用(Gray \& Spies, 1996)。林窗不仅随时间推移而发 生变化(Runkle, 1982), 而且也存在空间差异, 具有 一定的地形格局特征(藏润国等, 1999)。林窗的形成 和变化构成了森林景观的流动镶嵌结构, 对植被的 正常更新具有重要作用。因此, 合理、精确地确定 林窗特征, 研究其形成机制以及空间分布, 无论在 森林经营与管理还是在森林生态精细研究中都显 得十分重要。

林窗特征以及理解林窗结构格局与生态学过 程的相互作用, 在生态学研究中具有十分重要的意 义。从1947年Watt首次提出林窗一词至今, 林窗与 林窗动态研究已取得很大进展。从林窗模型(桑卫国 等, 1999)、林窗特征(梁晓东和叶万辉, 2001)、林窗 动态及更新(王家华和李建东, 2006)、林窗土壤养分 (沙丽清和曹敏, 1999)、林窗与物种多样性(Crawley, 2004)、林窗干扰和热力学特征(管云云等, 2016), 到 林窗的动态和竞争(Brokaw, 1985)、林窗在维持生物 多样性中的作用(Gray \& Spies, 1996)、林窗中幼苗 的更新和生长动态(Kenneth, 1992)、林窗干扰和更 新动态(Hubell et al, 1999)、林窗对动物的影响、林 窗微环境及树种的响应(Spies \& Franklin, 1989)、人 造林窗和人工模拟林窗环境对幼苗生长的影响等
方面都进行了大量的研究。这些研究在 20 世纪 80-90年代达到高峰, 但近年来却突然减少。究其原 因, 其中一个重要方面是技术手段并未能随时代的 发展而实现突破, 使得当前林窗特征测量的准确性 仍然不足且可监测范围过小。

传统基于地面的林窗测量方法由于受所获得 的数据精度差、人力成本高、覆盖范围小等限制, 很 难应用到整个森林群落, 尤其是相对密闭的亚热带 和热带森林群落(Larjavaara \& Muller-Landau, 2013)。 现有的遥感影像由于造价高, 如直升飞机和激光雷 达(Müller, 2008), 或Landset卫星遥感数据等辨识度 不够精细, 无法达到小尺度范围的群落生态学研究 的要求。最近在多个国家建立的冠层塔吊(canopy crane)观测系统可以长期、近距离对冠层结构和功 能进行调查, 但由于这些设备价格昂贵、监测范围 较小等, 很难得到广泛应用(Stork et al, 1997; Pennisi, 2005)。轻量级无人机兼具及时和低成本的优点, 开始广泛应用于各学科的研究中。本研究在Zhang 等(2016)利用无人机分析林冠结构等研究取得良好 成果中得到启示, 将无人机应用到林窗研究中。

常绿润叶林是湿润亚热带季风气候条件下孕 育出的地带性植被, 是亚热带地区的地域性标志植 被类型(de Vries，1986)。我国分布着世界上面积最 大的亚热带常绿阔叶林, 这也是世界上发生古老、 类型丰富、结构复杂的极具代表性的植被类型(吴征 镒，1980; 李昌华, 1997; 包维楷等, 2001), 该区域 也是植物群落和生物多样性保护的关键地区之一 (沈泽昊等, 2001)。研究常绿阔叶林林窗分布特征以 及林窗下物种更新的特点, 对常绿阔叶林多样性的 保护和维持有重要意义。

广东肇庆鼎湖山南亚热带常绿阔叶林是 20 世 纪40年代大树遭砍伐破坏后, 通过封山而自然恢复 
起来的次生林。为了应对台风暴雨等自然干扰, 加 之沟、脊相间的复杂地貌条件, 形成了独特的林窗 格局。研究林窗的分布特征对维持森林群落的物种 共存与揭示该区域森林植被动态及物种多样性维 持机制具有重要意义。鼎湖山自然保护区南亚热带 常绿榈叶林 20 ha动态监测样地(以下简称为鼎湖山 大样地)建立于 2005 年, 并于 2010 年和 2015 年完成 两次复查。十几年来多位研究人员在该样地进行了 大量关于森林群落方面的研究, 其中关于分布格局 与结构方面的研究包括: 生境与物种分布的关系 (刘文平等, 2011; Wang et al, 2012; Lin et al, 2013; Bin et al, 2015)、群落谱系结构(Pei et al, 2011; Huang et al, 2014)、群落遗传多样性空间格局(Wang et al, 2012，2016)等, 但还没有关于林窗分布格局的深入 研究。以林窗作为森林群落构建的重要起点, 开展 南亚热带常绿阔叶林的林窗特征、分布格局和森林 更新动态规律研究, 能够阐明林窗特征对物种共 存、种群更新和群落演替的影响, 为森林的保护与 可持续发展提供科学依据, 具有重要的理论和现实 意义。

本研究以鼎湖山大样地为研究对象, 在以往研 究的基础上, 尝试利用轻量级无人机空中拍摄影像, 通过航拍图像处理技术分析样地林窗的几何特征 和空间分布格局, 为进一步研究南亚热带森林物种 共存及生物多样性维持机制的研究奠定基础。并希 望能通过本研究为利用无人机进行林窗及林冠监 测找到一个行之有效的方法, 进而建立利用无人机 进行森林群落林冠变化与格局的监测技术体系, 以 期实现林窗与林下群落动态变化的同步监测, 为深 入了解鼎湖山南亚热带常绿润叶林的演替规律以及 合理经营提供科学依据。

\section{1 材料和方法}

\section{1 研究区域及样地概况}

鼎湖山国家级自然保护区位于广东省肇庆市 鼎湖区, 面积 $1,155 \mathrm{ha}$, 属低山丘陵地貌, 平均海拔 450-600 m, 最高峰鸡笼山海拔为 $1,000.3 \mathrm{~m}$; 山体 陡峭, 坡度多在 $30^{\circ}-45^{\circ}$ 之间。该地区属南亚热带湿 润季风气候, 冬夏气候交替明显, 年平均温度 20.9 ${ }^{\circ} \mathrm{C}$, 年均相对湿度 $81.5 \%$, 年均蒸发量 $1,115 \mathrm{~mm}$, 年 均降水量 $1,956 \mathrm{~mm}$, 但分布不均。鼎湖山森林群落 物种丰富, 植被类型复杂多样, 不仅包括典型的南
亚热带地带性森林植被一一季风常绿阔叶林, 其他 诸如山地常绿阔叶林、沟谷雨林、河岸林、混交林、 马尾松(Pinus massoniana)林和常绿灌层等次生植 被类型也错落分布其中(彭闪江等, 2003)。土壤类型 主要有赤红壤和黄壤, 赤红壤分布在海拔 $300 \mathrm{~m}$ 或 $350 \mathrm{~m}$ 以下; 海拔 $300 \mathrm{~m}$ 或 $350 \mathrm{~m}$ 至 $600 \mathrm{~m}$ 之间为山地 红壤; 黄壤分布于海拔600-980 m (何宜庚, 1983)。

\section{2 样地设置及调查方法}

按照国际通用的CTFS (Center for Tropical Forest Science)样地建设规范(Condit，1998), 于2005年 由中国科学院华南植物园在鼎湖山建立了一个 20 ha的永久森林动态监测样地。该样地是中国森林生 物多样性监测网络(CForBio, www.cfbiodiv.org)中第 一批建立的 4 个监测样地之一。以鼎湖山 20 ha样地 的西南角为原点, 用全站仪将其划分成 500 个 $20 \mathrm{~m}$ $\times 20 \mathrm{~m}$ 的样方, 再进一步将每个 $20 \mathrm{~m} \times 20 \mathrm{~m}$ 的样方 细分为 16 个 $5 \mathrm{~m} \times 5 \mathrm{~m}$ 的小样方。以每个 $5 \mathrm{~m} \times 5 \mathrm{~m}$ 小 样方为一个基本测树单元(杨庆松等, 2011)。调查对 象为样方内所有胸径 $(\mathrm{DBH}) \geq 1 \mathrm{~cm}$ 的木本植物, $\mathrm{DBH} \geq 3 \mathrm{~cm}$ 的个体用胸径尺测量其胸径, $1 \mathrm{~cm} \leq$ $\mathrm{DBH}<3 \mathrm{~cm}$ 的个体则用数显游标卡尺测量。均在高 度 $1.3 \mathrm{~m}$ 处测量, 以减少误差。调查内容包括每株植 物的种类、胸径、树高、冠幅、样格内坐标、样方 编号、样格编号、植物生长状况等。 $\mathrm{DBH} \geq 1 \mathrm{~cm}$ 的 萌枝、分枝按照同样方法挂牌测量, 并记录萌枝、 分枝的母株编号(叶万辉等, 2008)。

通过指示物种大致定位并计算每个 $20 \mathrm{~m} \times 20 \mathrm{~m}$ 样方的相对年龄, 以地形图的山脊为走向, 确定成 熟林和过熟林的分界线, 并将鼎湖山大样地划分为 成熟林和过熟林两个斑块。成熟林一部分是在 20 世 纪40年代通过封山而自然恢复起来的次生林。庆云 寺附近的样地属于过熟林, 因为宗教保护得以从明 朝较完整地保存至今。成熟林面积 $11.8 \mathrm{ha}$, 包括295 个 $20 \mathrm{~m} \times 20 \mathrm{~m}$ 样方; 过熟林面积 $8.2 \mathrm{ha}$, 包括 205 个 $20 \mathrm{~m} \times 20 \mathrm{~m}$ 样方(练琚愉等, 2015)。根据海拔、坡度、 坡面、坡向等地形因子将鼎湖山大样地划分成 5 个 生境, 分别为高谷、高坡、山脊、低谷、低坡(Wang et al, 2012)。5种生境类型中, 低谷面积最大, 包括 173 个 $20 \mathrm{~m} \times 20 \mathrm{~m}$ 样方, 共 $6.92 \mathrm{ha}$; 山脊面积最小, 包含 63 个 $20 \mathrm{~m} \times 20 \mathrm{~m}$ 样方, 共 $2.52 \mathrm{ha}$ 。生境之间的 面积相差较大, 分布不均匀, 其中高坡生境植株密 度显著大于大样地整体平均密度。 


\section{3 无人机航测}

采用2016年6月由无人机大疆精灵3 (大疆公司 出产的国产无人机, 易操作, 价格低)所拍摄的鼎湖 山大样地遥感影像进行数据提取。拍摄高度约 450 $\mathrm{m}$, 属于低空拍摄, 获取影像不受大气因素干扰。影 像具有红 $(R)$ 、绿 $(\mathrm{G})$ 、蓝 $(B) 3$ 种波段, 并使用Pix $4 \mathrm{D}$ mapper无人机航测数据处理系统进行数据处理, 形 成正射影像图。航拍照片利用RTK像控选取多个控 制点, 对77张照片拼接进行几何校正, 空间分辨率 达 $0.1 \mathrm{~m}$ 。

\section{4 影像处理}

利用森林阴影的光学特性, 在亮度(I)、色度 $(H)$ 、饱和度 $(S)$ 空间对阴影区域亮度、饱和度和色 调值进行匹配补偿, 去除阴影(李宇昊和石田, 2014)。同时将红、绿、蓝3波段进行组合运算(汪小 钦, 2015), 克服因树冠表面不光滑造成的色彩差 异。结合遥感图像监督分类, 将每个像元根据其在 不同波段的光谱亮度、空间结构特征按照最大似然 法分类, 划定林窗区域和不同林冠区域。

影像处理使用Envi 5.1和ArcGIS 10.1, 根据以 往的研究(Hubbell et al, 1999), 将林窗定义为面积 大于 $2 \mathrm{~m}^{2}$ 、树高低于 $10 \mathrm{~m}$ 的连续区域, 林窗限定高 度相当于亚冠层高度 $(10-15 \mathrm{~m})$ 的下限, 较符合我 国常绿阔叶林的客观情况(宋永昌, 2004)。由于 Hubbell等(1999)以 $25 \mathrm{~m}^{2}$ 为最小林窗的界限, 所以本 研究也以此为界, 将面积 $25 \mathrm{~m}^{2}$ 以下的林窗称为小 林窗，其余称之为大林窗。

\section{5 数据分析}

\subsection{1 林窗特征参数}

林冠空隙的大小是林窗的空间指标, 也是研究 林窗环境和更新的最重要的一个指标(朱教君, 2005; Hunter et al, 2015)。林窗的大小结构是指大小不同 的林窗数量分配格局, 可通过林窗的数量和面积进 行表述。本研究涉及的林窗特征参数包括: (1)林窗 面积, 指利用影像处理提取出的林窗多边形面积, 由ArcGIS 10.1软件在图上测算而得; (2)林窗空隙率, 指林窗面积占样地面积的百分比, 指示林窗干扰的 强度(de Vries, 1986); (3)林窗密度, 指单位样地面积 (1 ha)的林窗数量, 反映林窗的形成和周转速度(沈 泽吴等, 2001)。绘图通过地理信息系统软件A ArcGIS 10.1 完成, 将林窗面积、地理坐标等数据从ArcGIS 10.1中导出, 利用R 3.3.5 软件进行数据分析整合。在
林窗判定时, 为了便于统计, 根据鼎湖山大样地林 窗大小的实际情况以及Hubbell等(1999)对于林窗大 小的分类方法进行分类分析。

\subsection{2 林窗的地形因子}

计算鼎湖山大样地所有样方的海拔、坡度、坡 向以及凹凸度 4 个地形因子, 并根据这些数值划分 5 种不同的生境类型：高坡、高谷、低坡、低谷和山 脊(Wang et al, 2012)。根据已有地形因子数据, 通过 ArcGIS 10.1软件计算林窗所在样方的坡度、坡向和 凹凸度作为林窗的坡度、坡向(坡向从 $0^{\circ}-180^{\circ}, 0^{\circ}$ 表 示正北, $180^{\circ}$ 表示正南)和凹凸度, 并对海拔数据进 行Kriging插值, 将海拔数据栅格化为 $1 \mathrm{~m} \times 1 \mathrm{~m}$ 尺 度，计算林窗区域的平均海拔。为进一步分析不同 生境及不同成熟度对林窗面积的影响, 按不同生境 对林窗面积进行单因素方差分析，按照不同成熟度 对林窗面积进行 $t$ 检验, 对不同地形因子的林窗面 积进行相关性分析。以上检验与分析均利用 R 3.3.5 软件完成, 显著性水平设定为 $\alpha=0.05$ 。

由于某些林窗既位于成熟林也位于过熟林, 为 便于统计, 在讨论不同成熟度林分林窗情况时将其分 别记为两个不同的林窗, 这可能导致成熟林与过熟林 的林窗总数略大于大样地整体林窗总数, 因对整体结 果影响很小, 故忽略不计。不同生境林窗也是如此。

\section{2 结果}

\section{1 大样地林窗面积大小与分布特征}

鼎湖山大样地 20 ha面积范围内共有林窗 715 个 (图1), 总面积 $27,436.76 \mathrm{~m}^{2}$, 平均面积 $38.37 \mathrm{~m}^{2}$, 最 大为 $1,440.87 \mathrm{~m}^{2}$, 最小 $2.44 \mathrm{~m}^{2}$; 样地林窗空隙率为 $13.72 \%$, 密度为 35.75 个 $/ \mathrm{ha}$ 。将林窗面积划分为 6 类 (表1), 发现样地内多为面积较小的林窗, 其中小于 $25 \mathrm{~m}^{2}$ 的林窗数达 442 个, 占林窗总数的 $61.82 \%$, 总 面积为 $5,236.09 \mathrm{~m}^{2}$; 面积较大的林窗出现频率较小, 大于 $100 \mathrm{~m}^{2}$ 的林窗只有 46 个, 占林窗总数的 $6.43 \%$, 面积为 $11,607.42 \mathrm{~m}^{2}$; 大于 $400 \mathrm{~m}^{2}$ 的林窗数量仅占 林窗总数的 $0.69 \%$ 。该区域林窗呈负指数分布，表现 出以中小型为主、小林窗多大林窗少的特点(图2)。

\section{2 不同成熟度林分中的林窗面积及分布特征}

过熟林林窗 240 个, 总面积为 $12,578.52 \mathrm{~m}^{2}$, 平 均面积 $52.41 \mathrm{~m}^{2}$, 林窗空隙率为 $15.34 \%$, 密度为 29.27 个 $/ \mathrm{ha}$, 其中小于 $25 \mathrm{~m}^{2}$ 的林窗 133 个。成熟林林 窗 484 个, 总面积为 $15,068.57 \mathrm{~m}^{2}$, 平均面积 


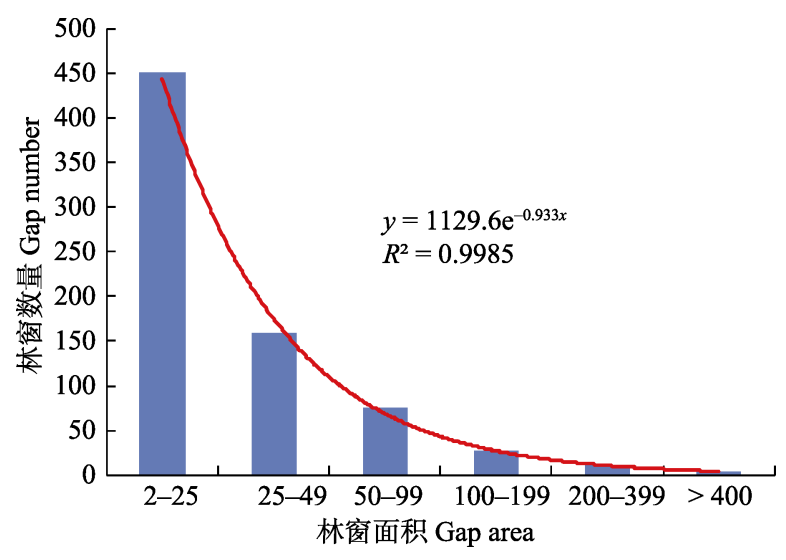

图1 鼎湖山南亚热带常绿阔叶林20 ha动态监测样地林窗 空间分布特征

Fig. 1 Spatial distribution characteristics of gaps in the 20 ha dynamics plot of subtropical evergreen broad-leaved forest in Dinghushan

$31.13 \mathrm{~m}^{2}$, 林窗空隙率为 $12.77 \%$, 林窗密度为 41.01 个/ha，其中小于 $25 \mathrm{~m}^{2}$ 的林窗 318 个(表2)。 $t$ 检验结果 表明, 成熟林与过熟林林窗面积有显著性差异, 大 林窗在过熟林出现的概率较大, 其平均林窗面积和 林窗空隙率也大于成熟林。

\section{3 不同生境中的林窗面积与分布特征}

5 种生境类型中，高谷林窗 151 个，总面积为
表1 鼎湖山南亚热带常绿阔叶林20 ha动态监测样地林窗 分类与数据特征

Table 1 Gap classification and data characteristics in 20 ha plot of subtropical evergreen broad-leaved forest of Dinghushan

\begin{tabular}{lllll}
\hline $\begin{array}{l}\text { 林窗面积 } \\
\text { Gap area }\left(\mathrm{m}^{2}\right)\end{array}$ & $\begin{array}{l}\text { 林窗数量 } \\
\text { Gap number }\end{array}$ & $\begin{array}{l}\text { 数量比例 } \\
\text { Quantity ratio }\end{array}$ & $\begin{array}{l}\text { 面积比例 } \\
\text { Area ratio }\end{array}$ & $\begin{array}{l}\text { 林窗类型 } \\
\text { Gap type }\end{array}$ \\
\hline $2-25$ & 442 & $61.82 \%$ & $19.08 \%$ & 小林窗 Small gap \\
$25-49$ & 151 & $21.12 \%$ & $19.37 \%$ & 大林窗 Large gap \\
$50-99$ & 76 & $10.63 \%$ & $19.24 \%$ & 大林窗 Large gap \\
$100-199$ & 30 & $4.20 \%$ & $14.51 \%$ & 大林窗 Large gap \\
$200-399$ & 11 & $1.54 \%$ & $11.01 \%$ & 大林窗 Large gap \\
$>400$ & 5 & $0.69 \%$ & $16.79 \%$ & 大林窗 Large gap \\
合计 Total & 715 & $100 \%$ & $100 \%$ & - \\
\hline
\end{tabular}

$7,230.81 \mathrm{~m}^{2}$; 高坡林窗 122 个，总面积为 $5,070.55 \mathrm{~m}^{2}$; 山脊林窗 126 个, 总面积为 $3,370.54 \mathrm{~m}^{2}$; 低谷林窗 266 个，总面积为 $14,968.91 \mathrm{~m}^{2}$; 低坡林窗 226 个, 总 面积为 $8,280.87 \mathrm{~m}^{2}$ (表3)。低谷的林窗面积与其他生 境呈显著性差异, 大面积的林窗主要出现在低谷, 不过总体还是呈小林窗多、大林窗少的特点(表4)。

\section{4 林窗面积与地形因子的相关性}

林窗面积与地形因子的相关性分析结果表明, 林窗面积与海拔的Pearson相关性为 -0.096 , 呈显著 负相关，即低海拔段林窗的空隙率和密度显著大于

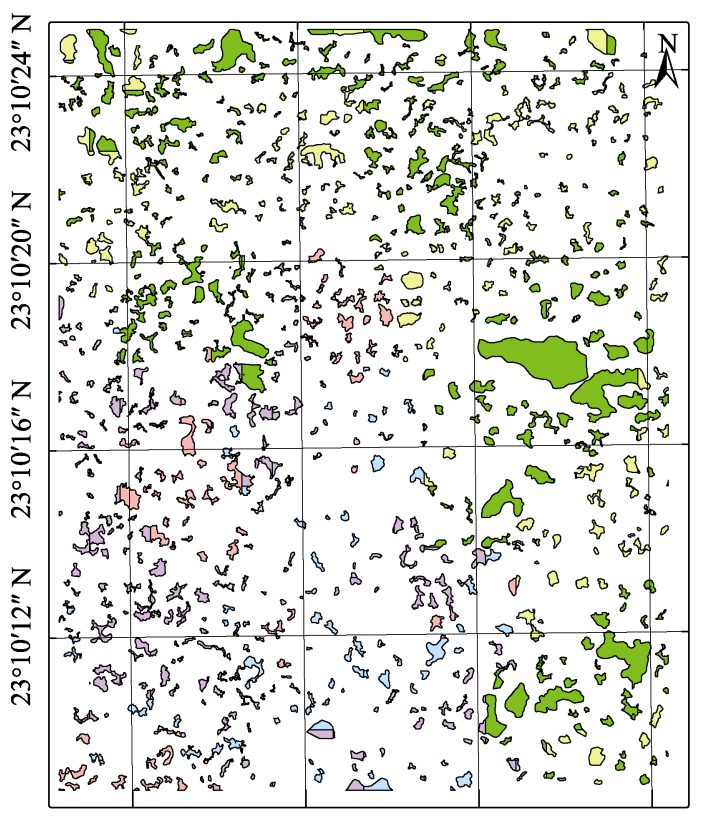

$112^{\circ} 32^{\prime} 8^{\prime \prime} \mathrm{E} \quad 112^{\circ} 32^{\prime} 12^{\prime \prime} \mathrm{E} \quad 112^{\circ} 32^{\prime} 16^{\prime \prime} \mathrm{E} 112^{\circ} 32^{\prime} 20^{\prime \prime} \mathrm{E}$

(B)

图2 不同成熟度(A)及不同生境(B)中的林窗分布图。(A)粉色=成熟林; 蓝色=过熟林。(B)紫色=高谷; 蓝色=高坡; 粉色=山 脊; 绿色=低谷; 黄色=低坡。

Fig. 2 Gap distribution at different maturity levels (A) and in different habitats (B). (A) Pink = Mature forest; Blue = Over-mature forest. $(\mathrm{B})$ Purple $=$ High valley; Blue $=$ High slope; Pink $=$ Ridge; Green $=$ Low valley; Yellow $=$ Low slope . 
表2 不同成熟度林分中的林窗空隙率和林窗密度

Table 2 Gap fraction and gap density under different maturity stands

\begin{tabular}{|c|c|c|c|c|c|c|c|c|}
\hline \multirow[t]{2}{*}{ 类型 Type } & \multicolumn{2}{|c|}{ 数量比例 Quantity ratio } & \multicolumn{2}{|c|}{ 面积比例 Area ratio } & \multicolumn{2}{|c|}{ 空隙率 Gap fraction } & \multicolumn{2}{|c|}{ 密度 Gap density (no./ha) } \\
\hline & $\begin{array}{l}\text { 小林窗 } \\
\text { Small gap } \\
\end{array}$ & $\begin{array}{l}\text { 大林窗 } \\
\text { Large gap } \\
\end{array}$ & $\begin{array}{l}\text { 小林窗 } \\
\text { Small gap } \\
\end{array}$ & $\begin{array}{l}\text { 大林窗 } \\
\text { Large gap } \\
\end{array}$ & $\begin{array}{l}\text { 小林窗 } \\
\text { Small gap } \\
\end{array}$ & $\begin{array}{l}\text { 大林窗 } \\
\text { Large gap } \\
\end{array}$ & $\begin{array}{l}\text { 小林窗 } \\
\text { Small gap } \\
\end{array}$ & $\begin{array}{l}\text { 大林窗 } \\
\text { Large gap }\end{array}$ \\
\hline $\begin{array}{l}\text { 过熟林 } \\
\text { Over-mature forest }\end{array}$ & $55.42 \%$ & $44.58 \%$ & $13.20 \%$ & $86.80 \%$ & $2.03 \%$ & $13.31 \%$ & 16.22 & 13.05 \\
\hline 成熟林 Mature forest & $65.70 \%$ & $34.30 \%$ & $24.20 \%$ & $75.80 \%$ & $3.09 \%$ & $9.68 \%$ & 26.95 & 14.06 \\
\hline
\end{tabular}

表3 不同生境类型中的林窗数量和林窗空隙率

Table 3 Number of gaps and gap fraction under different habitat types

\begin{tabular}{lllll}
\hline 生境类型 Habitat type & 样地面积 Plot area (ha) & 林窗数量 Gap number & 林窗空隙率 Gap fraction & $\begin{array}{l}\text { 林窗平均面积 } \\
\text { Average gap area }\left(\mathrm{m}^{2}\right)\end{array}$ \\
\hline 大样地 Whole plot & 20 & 715 & $13.72 \%$ & 38.37 \\
高谷 High valley & 3.08 & 151 & $10.45 \%$ & 47.89 \\
高坡 High slope & 2.92 & 122 & $16.46 \%$ & 41.56 \\
山脊 Ridge & 2.52 & 126 & $5.11 \%$ & 26.75 \\
低谷 Low valley & 6.92 & 266 & $51.26 \%$ & 56.27 \\
低坡 Low slope & 6.60 & 226 & $32.86 \%$ & 36.64 \\
\hline
\end{tabular}

表4 不同生境类型中的林窗空隙率及林窗密度

Table 4 Gap fraction and gap density under different habitats

\begin{tabular}{|c|c|c|c|c|c|c|c|c|}
\hline \multirow[t]{2}{*}{$\begin{array}{l}\text { 生境类型 } \\
\text { Habitat type }\end{array}$} & \multicolumn{2}{|c|}{$\begin{array}{l}\text { 林窗数量比例 } \\
\text { Quantity ratio (\%) }\end{array}$} & \multicolumn{2}{|c|}{$\begin{array}{l}\text { 林窗面积比例 } \\
\text { Area ratio (\%) }\end{array}$} & \multicolumn{2}{|c|}{$\begin{array}{l}\text { 林窗空隙率 } \\
\text { Gap fraction (\%) }\end{array}$} & \multicolumn{2}{|c|}{$\begin{array}{l}\text { 林窗密度 } \\
\text { Gap density (no./ha) }\end{array}$} \\
\hline & $\begin{array}{l}\text { 小林窗 } \\
\text { Small gap }\end{array}$ & $\begin{array}{l}\text { 大林窗 } \\
\text { Large gap }\end{array}$ & $\begin{array}{l}\text { 小林窗 } \\
\text { Small gap }\end{array}$ & $\begin{array}{l}\text { 大林窗 } \\
\text { Large gap }\end{array}$ & $\begin{array}{l}\text { 小林窗 } \\
\text { Small gap }\end{array}$ & $\begin{array}{l}\text { 大林窗 } \\
\text { Large gap }\end{array}$ & $\begin{array}{l}\text { 小林窗 } \\
\text { Small gap }\end{array}$ & $\begin{array}{l}\text { 大林窗 } \\
\text { Large gap }\end{array}$ \\
\hline 大样地 Whole plot & 61.81 & 38.19 & 19.08 & 80.92 & 2.62 & 11.10 & 22.10 & 13.65 \\
\hline 高谷 High valley & 58.28 & 41.72 & 14.02 & 85.98 & 1.47 & 8.98 & 12.72 & 9.10 \\
\hline 高坡 High slope & 59.02 & 40.98 & 17.57 & 82.43 & 2.89 & 13.57 & 23.38 & 16.23 \\
\hline 山脊 Ridge & 69.05 & 30.95 & 29.71 & 70.29 & 1.52 & 3.59 & 13.18 & 5.91 \\
\hline 低谷 Low valley & 49.62 & 50.38 & 11.59 & 88.41 & 5.94 & 45.32 & 45.21 & 45.89 \\
\hline 低坡 Low slope & 61.06 & 38.94 & 19.59 & 80.41 & 6.43 & 26.43 & 54.76 & 34.92 \\
\hline
\end{tabular}

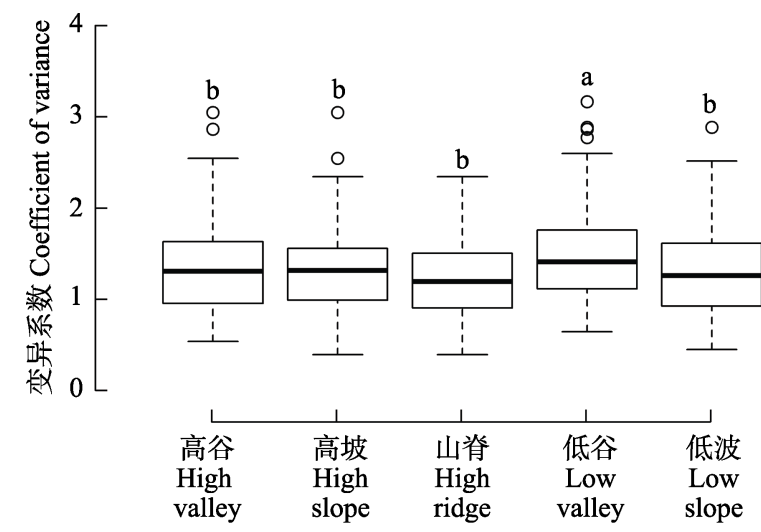

生境类型 Habitat type

图3 不同生境中林窗面积的差异。不同字母表示差异显著。 Fig. 3 Difference of gap area in different habitats. Different letters indicates significant difference.
中、高海拔段；与凹凸度的Pearson相关性为 -0.179 , 呈显著负相关; 与坡度和坡向的Pearson相关性分 别为 0.080 和 0.074 , 均呈显著正相关(图3)。林窗空隙 率与林窗密度在海拔和坡位梯度上有显著差异，呈 显著的负相关, 表现为中低海拔段显著大于高海拔 段，沟谷显著大于山坡。

\section{3 讨论}

\section{1 鼎湖山大样地林窗的基本特征}

鼎湖山大样地林窗的负指数分布与目前其他 针对常绿阔叶林(Yamamoto, 1992; Holmes, 1995)、 热带雨林(臥润国, 1998)等研究的结果一致, 也与针 叶林的研究结果类似(夏冰等, 1996)。南亚热带常绿 
阔叶林中单个林窗的面积多在 $50 \mathrm{~m}^{2}$ 以下, 本次调 查的鼎湖山大样地林窗平均面积和林窗空隙率分别 为 $38.37 \mathrm{~m}^{2}$ 和 $13.72 \%$, 林窗的最大和最小面积分别 为 $1,440.87 \mathrm{~m}^{2}$ 和 $2.44 \mathrm{~m}^{2}$ 。在该样地中, 以 $25-49 \mathrm{~m}^{2}$ 林窗所占的面积比例最大, 为 $19.37 \%$, 而以 $25 \mathrm{~m}^{2}$ 以 下林窗所占的数量比例最大, 为 $61.82 \%$ 。与我国其 他大样地相比, 鼎湖山大样地中的这些数值都远小 于东北阔叶红松林, 也小于海南岛热带山地雨林(臓 润国, 1998)。这可能是由于南亚热带森林的林冠层 树木的冠幅大都较小, 而红松林和热带山地雨林林 冠层或超冠层的树冠较大的缘故。与其他地区常绿 阔叶林林窗面积相比, 鼎湖山大样地的林窗面积小 于天童山(平均面积137.82 $\mathrm{m}^{2}$ ) (张志国等, 2013)、哀 牢山(268.4 $\mathrm{m}^{2}$ ) (李贵才等, 2003)和万木林 $\left(229.7 \mathrm{~m}^{2}\right.$ ) (闯淑君等, 2004), 林窗空隙率与天童山相差不大, 但比万木林 $(50.9 \%)$ 小很多。原因除了林窗一直处于 不断的动态变化中之外, 还可能是由于林窗面积的 计算方法不同所致。以往的林窗调查基本都是直接 的实地调查, 将林窗形状视为椭圆形, 通过测量林 窗长、短轴的长度来计算其面积, 这些都可能给林 窗面积计算带来偏差, 且偏离值差异较大。而实际 上林窗多为不规则的多边形且林窗形状多样。利用 此种方法计算面积来比较和说明林窗环境的差异 时可能失真。本文的林窗面积是利用A $\mathrm{ArCGIS}$ 直接计 算无人机航拍照片所得, 在一定程度上减小了由于 林窗形状不同可能带来的误差。

林窗形成木的大小直接影响着林窗的大小 (Hubbell \& Foster, 1986)。树木只有达到一定径级并 到达林冠层后, 才有可能在死亡或受损后形成林窗, 因此林窗形成木的径级和高度与林分的径级和高 度直接相关(van Bloem et al, 2006)。树木越高、径 级越大, 冠幅也越大, 树木折干、掘根后所形成的 林窗也相应较大。鼎湖山常绿阔叶林群落高度一般 在 $10 \mathrm{~m}$ 以下, 调查样地胸径大于 $1 \mathrm{~cm}$ 的个体平均胸 径为 $5.02 \mathrm{~cm}$; 天童山样地群落平均胸径 $5.66 \mathrm{~cm}$; 万 木林群落平均胸径约 $26 \mathrm{~cm}$ (间淑君等, 2004)。由于 台风是鼎湖山林窗干扰的主要外部驱动力, 长期的 强风干扰会对群落的垂直结构造成影响, 促使乔木 的构型趋于灌木化(van Bloem et al, 2006), 导致群落 高度偏低、径级偏小, 所形成的林窗平均面积和空隙 率也相对较小(张志国等, 2013)。

\section{2 鼎湖山大样地林窗分布格局的形成原因及其规律}

林窗成因是环境因子对植物群落动态影响的 一个重要体现。常绿阔叶林林窗的形成原因较为复 杂, 小径木的死亡可能是因竞争而导致生存被抑制 的结果, 但大径级的较高冠层木的死亡则可能是由 于树木生长发育以及与地形、风等自然因子相互作 用的结果(Spies \& Flanklin, 1989)。实地调查和长期 的野外监测表明, 鼎湖山不同演替阶段中的林窗成 因是多方面的，有暴风雨引起的山体滑坡、雷击等 气候性原因，也有小尺度火灾、人工砍伐、树木折 断(自然衰老)、虫害引起的树木枯倒等方面的原因。 据报道, 鼎湖山林窗的主要成因依出现频度高低依 次为: 虫害、滑坡、雷击、暴风雨、火灾和人工砍 伐(彭闪江等, 2003)。在实地调查林窗形成的过程中 发现, 鼎湖山大样地的很多林窗都不止一株倒木, 大部分林窗是由多株树木倒下形成，这些倒木的死 亡方式几乎与乱砍乱伐等人为因素无关, 它们的大 小也不尽相同。可见, 鼎湖山的林窗主要成因来自自 然干扰，人为干扰(火灾和人工砍伐)所占比例较小。

排除人为干扰因素, 在温带森林中以掘根方式 形成的林窗最多, 而在热带和亚热带森林中以折干 方式形成的林窗最多, 从温带、亚热带到热带, 干 中折断的比例呈增加的趋势, 即由温带的 $1.60 \%$, 亚 热带的 $24.41 \%$, 到热带的 $32.47 \%$ (刘静艳等, 1999; 梁晓东和叶万辉, 2001)。这种林窗形成方式的变化 趋势可能主要与各森林所处的自然气候条件有关。 鼎湖山地处亚热带, 大风特别是台风出现的频率和 强度都远大于温带, 所以树木折断的比例较大。这 里林窗形成最为普遍的原因是由主林层树木折干 所致，可分为干中和干基折断两种形式。干中折断 (即折断的高度在距树基 $1.5 \mathrm{~m}$ 以上)大多是强大风 力作用的结果, 而干基折断不仅因为强大风力的作 用, 还可能因为树木衰老到一定程度, 基部强度减 弱, 稍有外力作用(风或重力)即从基部折断。林窗形 成的第二大原因是枯立木, 即树木死亡后, 其枝叶 脱落, 但主干仍直立于林中形成站杆。

鼎湖山大样地成熟林林窗数目虽大于过熟林, 但林窗的平均面积和林窗空隙率都小于过熟林, 这 不仅与成熟林和过熟林本身所占面积相关, 还与林 窗形成的原因有关。过熟林处于演替后期, 树木年 龄较大, 许多大树开始衰老死亡。而成熟林中的树 木还在生长, 中径级个体重要值较高, 大径级个体 
数远小于过熟林。低谷林窗空隙率及林窗平均面积 显著大于其他生境, 原因是低谷地段根系土层不稳 定, 冲刷发生频繁, 加之两侧边坡坡度陡, 土壤含 水量大, 低谷内幼树较多, 而胸径大于 $8 \mathrm{~cm}$ 的乔木 死亡数达 864 株, 补员数却仅有 337 株; 树木根系大 多较浅, 台风带来的强降雨极易造成沟谷内小范围 的滑坡(Hunter \& Parker, 1993; Almquist, 2002; 谢玉 涁等, 2012), 这增加了树木掘根倒伏的概率, 导致 沟谷内林窗的面积和密度偏大。随着坡位梯度升高, 林木个体密度随之增大, 林窗面积也就相对减小。

不同成因形成的林窗面积不同, 林窗形状的变 异也较大, 大多数呈不规则的多边形。从水平面上 来看, 样地内林窗的形状是不规则的。在航拍照片 上，一般形成初期的林窗其平面形态表现为等轴或 近等轴的圆、椭圆或其他不规则的浑圆形(Whitmore, 1978; Taylor \& Qin, 1988; Yamamoto, 1992), 实地立 体观测形如“井”状。填充阶段的林窗则表现为不规 则的分枝脉状，实地观测为不规则的分枝脉状凹 陷。采用样地投影调查方法结合无人机航拍调查可 提高测定精度, 减小由于林窗形状和计算方法不同 产生的误差, 有利于不同林分调查结果的有效比较。

\section{3 地形因子对林窗面积分布的影响}

地带性植被的林窗特征是特殊干扰体系、复杂 地形格局以及林木结构相互作用的产物。因为地形 因子通过对外部能量的再分配, 调控着干扰的强度 和形式, 并间接影响着群落的组成和结构(彭闪江 等, 2003), 所以林窗特征及其格局可以从不同地形 因子的变化梯度上反映出来。低海拔地区因混生阔 叶树的倒伏形成的林窗面积更大, 因此低谷的林窗 空隙率、林窗密度均大于样地平均水平。本研究结 果较好地反映了这种规律。

\section{4 无人机在林窗研究中的应用与优势}

研究林窗与群落更新的首要条件是需要对林窗 的几何特征进行准确测量。用无人机航拍照片提取 林窗数据的优点有: (1)大范围样方数据采集可以在 短时间内完成, 不需要耗费大量人力、物力; (2)不受 人工操作、自然条件等因素的影响, 整体结果往往 更客观、稳定(胡理乐等, 2010); (3)在计算一些冠层 结构参数时, 可进行复杂的森林三维结构信息提取; (4)可以较好解决单个林窗样地尺度与多个林窗景 观尺度之间的推移问题, 在一定程度上达到群落生 态学研究的要求; (5)造价便宜且精度较高。由无人
机航拍照片获得林窗信息较以往常规方法更为便 捷, 可以准确描述林窗形态及其空间格局特征, 将其推广到森林干扰生态学领域, 并与森林大样 地长期、系统、全面的监测数据有效结合, 可为林 窗研究提供应用支撑并更好地回答群落更新的理 论问题, 使森林物种多样性维持机制得到更全面 的认识。

从森林循环理论的角度来看, 林窗的不断变化 在大景观尺度上存在不确定性: 一方面林冠的迅速 填充可使林窗快速郁闭; 另一方面林窗的产生使边 缘区域的树木对风等的干扰更加敏感，从而更容易 发生倒伏, 使林窗面积进一步增大(谭辉等, 2007)。 林窗研究无论是在物种共存还是群落构建中都有 着非常重要的作用。地面人工观测与运用先进手段 和技术连续自动采集数据相结合是当前发展的新 趋势(马克平, 2016)。本研究采用近地面遥感技术 —无人机作为林窗研究的新方法, 使鼎湖山南亚 热带常绿阔叶林林窗几何特征和空间格局的研究 更加深入, 有利于进一步分析鼎湖山植物群落的更 新等。同时, 无人机造价较低、飞行条件要求简单, 为实现大样地的全面监测提供了便利, 使样地监测 的频率大大提高, 不仅可以监测到不同年份、不同 季节的林窗群落结构特征, 还可以对林冠及其他特 征进行监测。

今后应加强以下几方面的研究：加强林窗形 成、填充和基本特征在全国乃至全球尺度上的研究， 推广无人机航拍与地面调查结合的监测技术; 考虑 立地条件、景观结构等因素, 结合演替过程分析森 林更新演替、稳定性和生产力以及森林的生态服务 功能的影响研究。

\section{参考文献}

Almquist BE, Jack SB, Messina MG (2002) Variation of the treefall gap regime in a bottomland hardwood forest: relationships with microtopography. Forest Ecology and Management, 157, 155-163.

Bao WK, Liu ZG, Yuan YF, Liu RD, Liu ZL (2001) Gap formation features of humid evergreen broad-leaved forest in central subtropical Wawushan Mountain, Sichuan Province, China. Chinese Journal of Applied Ecology, 12, 485-490. (in Chinese with English abstract) [包维楷, 刘照光, 袁亚 夫, 刘仁东, 刘朝禄 (2001) 瓦屋山中亚热带湿性常绿阔 叶林的林窗形成特征. 应用生态学报, 12, 485-490.]

Bin Y, John S, Wu LF, Li BH, Hao ZQ, Ye WH, He FL (2015) 
Species-habitat associations and demographic rates of forest trees. Ecography, 38, 1-8.

Brokaw N (1985) Gap-phase regeneration in a tropical forest. Ecology, 66, 682-687.

Condit R (1998) Tropical Forest Census Plots: Methods and Results from Barro Colorado Island, Panama and a Comparison with Other Plots. Springer, Berlin.

Connell JH (1978) Diversity in tropical rain forests and coral reefs. Science, 199, 1302-1310.

Crawley MJ (2004) Timing of disturbance and coexistence in a species-rich ruderal plant community. Ecology, 85, 32773288.

de Vries PG (1986) Sampling Theory for Forest Inventory. Springer, Berlin.

Gray AN, Spies TA (1996) Gaps size, within-gap position and canopy structure effects on conifer seedling establishment. Ecology, 84, 635-645.

Guan YY, Fei F, Guan QW, Chen B (2016) Advances in studies of forest gap ecology. Scientia Silvae Sinicae, 52, 91-99. (in Chinese with English abstract) [管云云, 费菲, 关庆伟, 陈斌 (2016) 林窗生态学研究进展。林业科学, 52, 91-99.]

He YG (1983) The soil of the Dinghu Moutain Natural Resevation, Guangdong Province. Journal of South China Normal University (Natural Science Edition), (1), 87-96. (in Chinese with English abstract) [何宜庚 (1983) 广东省鼎湖山 自然保护区的土壤. 华南师范大学学报(自然科学版), (1), 87-96. ]

Holmes TH (1995) Woodland canopy structure and the light response of juvenile Qercus lobata (Fagaceae). American Journal of Botany, 82, 1432-1442.

Hu LL, Li JS, Wu XP, Yan BQ, Zhu JJ, Luo JW, Xiao NW (2010) Review on methods of measuring geometric characteristics of forest gaps involving gap size, gap shape, and the height of canopy trees surrounding the gap. Acta Ecologica Sinica, 30, 1911-1919. (in Chinese with English abstract) [胡理乐, 李俊生, 吴晓莆, 间伯前, 朱教君, 罗建武, 肖 能文 (2010) 林窗几何特征的测定方法. 生态学报, 30, 1911-1919.]

Huang JX, Zhang J, Shen Y, Lian JY, Cao HL, Ye WH, Wu LF, Bin Y (2014) Different relationships between temporal phylogenetic turnover and phylogenetic similarity and in two forests were detected by a new null model. PLoS ONE, 9, e95703.

Hubbell SP, Foster RB, O'Brien ST, Harms KE, Condit R, Wechsler B, Wright SJ, de Lao SL (1999) Light-gap disturbances, recruitment limitation, and tree diversity in a neotropical forest. Science, 283, 554-557.

Hubbell SP, Foster RB (1986) Canopy Gaps and the Dynamics of a Neotropical Forest. Blackwell Scientific Publications, Oxford.

Hunter JC, Parker VT (1993) The disturbance regime of an old-growth forest in coastal California. Journal of Vegeta- tion Science, 4, 19-24.

Hunter MO, Keller M, Morton D, Cook Bruce, Lefsky M, Ducey M, Saleska S, Oliveira RC, Schietti J (2015) Structural dynamics of tropical moist forest gaps. PLoS ONE, 10, 1371.

Huston M (1979) A general hypothesis of species-diversity. The American Naturalist, 113, 81-101.

Kenneth PL (1992) Pattern of gap-phase replacement in a subalpine, old-growth forest. Ecology, 73, 657-669.

Larjavaara M, Muller-Landau HC (2013) Measuring tree height: a quantitative comparison of two common field methods in a moist tropical forest. Methods in Ecology and Evolution, 4, 793-801.

Li CH (1997) The distribution of evergreen broad-leaved forest in eastern Asia. Journal of Natural Resources, 2, 37-45. (in Chinese with English abstract) [李昌华 (1997) 亚洲东部 常绿阔叶林的分布. 自然资源, 2, 37-45.]

Li GC, He YT, Han XG (2003) Features of gaps of middle mountain moist evergreen broad-leaved forest in Ailao Mountain. Chinese Journal of Ecology, 22, 13-17. (in Chinese with English abstract) [李贵才，何永涛，韩兴国 (2003) 哀牢山中山湿性常绿阔叶林林窗特征研究. 生态 学杂志, 22, 13-17.]

Li YH, Shi T (2014) Estimating the canopy density through color features of aerial digital images. Journal of Northwest Forestry University, 29, 148-154. (in Chinese with English abstract) [李宇昊, 石田 (2014) 利用航空数码影像的色 彩特征估测森林郁闭度. 西北林学院学报, 29, 148-154.]

Lian JY, Chen C, Huang ZL, Cao HL, Ye WH (2015) Community composition and stand age in a subtropical forest, southern China. Biodiversity Science, 23, 174-182. (in Chinese with English abstract) [练琚愉, 陈灿, 黄忠良, 曹洪 麟, 叶万辉 (2015) 鼎湖山南亚热带常绿阔叶林不同成 熟度群落特征的比较. 生物多样性, 23, 174-182.]

Liang XD, Ye WH (2001) Advances in study on forest gaps. Journal of Tropical and Subtropical Botany, 9, 355-364. (in Chinese with English abstract) [梁晓东, 叶万辉 (2001) 林 窗研究进展. 热带亚热带植物学报, 9, 355-364.]

Lin GJ, Diana S, Gong GQ, Huang ZL, Ye WH, Wu LF (2013) Separating the effects of environment and space on tree species distribution: from population to community. PLoS ONE, 8, e56171.

Liu JY, Wang BS, Zang RG (1999) Gap formation and its characteristics in south subtropical evergreen broadleaved forest. Chinese Journal of Applied Ecology, 10, 385-388. (in Chinese with English abstract) [刘静艳, 王伯䔉, 藏润 国 (1999) 南亚热带常绿阔叶林林隙形成方式及其特征 的研究. 应用生态学报, 10, 385-388.]

Liu WP, Cao HL, Liu W, Lian JY, Wu LF (2011) Study on diversity of monsoon evergreen broad-leaved forest in different kinds of habitat in Dinghushan. Journal of Anhui Agricultural Sciences, 39, 16159-16163. (in Chinese with English abstract) [刘文平，曹洪麟，刘卫，练琚愉，吴林芳 
(2011) 鼎湖山季风常绿阔叶林不同生境物种多样性研 究. 安徽农业科学, 39, 16159-16163.]

Ma KP (2016) Biodiversity monitoring relies on the integration of human observation and automatic collection of data with advanced equipment and facilities. Biodiversity Science, 24, 1201-1202. (in Chinese) [马克平 (2016) 生物多样性监测 依赖于地面人工观测与先进技术手段的有机结合. 生物 多样性, 24, 1201-1202.]

Müller K, Boüttcher U, Meyer-Schatz F, Kage H (2008) Analysis of vegetation indices derived from hyperspectral reflection measurements for estimating crop canopy parameters of oilseed rape. Biosystems Engineering, 101, 172-182.

Pei NC, Lian JY, Erickson DL, Swenson NG, Kress WJ, Ye WH, Ge XJ (2011) Exploring tree-habitat associations in a Chinese subtropical forest plot using a molecular phylogeny generated from DNA barcode loci. PLoS ONE, 6, e21273.

Pennisi E (2005) What determines species diversity. Science, 309, 90.

Peng SJ, Huang ZL, Zhou GY, Zhou XY, Zhang C, He WQ (2003) Gap formation characteristics and its effects on sapling composition and diversity in Dinghushan biosphere reserve. Journal of Tropical and Subtropical Botany, 11, 229-235. (in Chinese with English abstract) [彭闪江, 黄忠 良, 周国逸, 周小勇, 张池, 贺握权 (2003) 鼎湖山林窗 形成特征及其对幼树组成和多样性的影响. 热带亚热带 植物学, 11, 229-235.]

Runkle JR (1982) Patterns of disturbance in some old-growth mesic forests of eastern North America. Ecology, 63, 1533-1546.

Sang WG, Ma KP, Chen LZ, Zheng Y (1999) A brief review on forest dynamics models. Chinese Bulletin of Botany, 16, 193-200. (in Chinese with English abstract) [桑卫国, 马克 平, 陈灵芝, 郑豫 (1999) 森林动态模型概论. 植物学通 报, 16, 193-200. ]

Sha LQ, Cao M (1999) Nutrients in treefall gap of tropical seasonal rainforest in Xishuangbanna. Journal of Northeast Forestry University, 27(6), 78-80. (in Chinese with English abstract) [沙丽清, 曹敏 (1999) 西双版纳热带季节雨林 林冠下及林窗中土壤养分对比研究. 东北林业大学学报, 27(6), 78-80.]

Shen ZH, Wang GF, Li DX (2001) Gap related disturbance in mixed mountain forests at Mt. Dalaoling in the Three Gorges. II. Topographic patterns. Acta Phytoecologica Sinica, 26, 149-156. (in Chinese with English abstract) [沈 泽吴, 王功芳, 李道兴 (2001) 三峡大老岭山地常绿落叶 阔叶混交林林隙干扰研究. II. 林隙干扰的地形格局. 植 物生态学报, 26, 149-156.]

Shugart HH (1984) A Theory of Forest Dynamics. SpringerVerlag, New York.

Song YC (2004) Tentative classification scheme of evergreen broad-leaved forest of China. Acta Phytoecologica Sinica, 28，435-448. [宋永昌 (2004) 中国常绿阔叶林分类试行
方案. 植物生态学报, 28, 435-448.]

Spies TA, Franklin JF (1989) Gap characteristics and vegetation response in coniferous forests of the Pacific Northwest. Ecology, 70, 543-545.

Stork O, Welzl H, Cremer H, Schachner M (1997) Increased intermale aggression and neuroendocrine response in mice deficient for the neural cell adhesion molecule (NCAM). European Journal of Neuroscience, 9, 1117-1125.

Tan H, Zhu JJ, Kang HZ, Hu LL (2007) A research review on forest gap disturbance. Chinese Journal of Ecology, 26, 587-594. (in Chinese with English abstract) [谭辉, 朱教君, 康宏樟, 胡理乐 (2007) 林窗干扰研究. 生态学杂志, 26, 587-594.]

Taylor AH, Qin ZS (1988) Regeneration patterns in old-growth Abies-Betula forests in the Wolong Natural Reserve, Sichuan, China. Journal of Ecology, 76, 1204-1218.

Tokeshi M (1999) Species Coexistence. Blackwell Science, Oxford.

van Bloem SJ, Lugo AE, Murphy PG (2006) Structural response of Caribbean dry forests to hurricane winds: a case study from Guánica Forest, Puerto Rico. Journal of Biogeography, 33, 517-523.

Wang JH, Li JD (2006) Advances in study on forest gaps. World Forestry Research, 19, 27-30. (in Chinese with English abstract) [王家华, 李建东 (2006) 林窗研究进展. 世 界林业研究, 19, 27-30.]

Wang XQ, Wang MM, Wang SQ, Wu YD (2015) Extraction of vegetation information from visible unmanned aerial vehicle. Transactions of the Chinese Society of Agriculture Engineering, 31, 152-159. (in Chinese with English abstract) [汪小钦, 王苗苗, 王绍强, 吴云东 (2015) 基于可见光波 段无人机遥感的植被信息提取. 农业工程学报, 31, 152-159.]

Wang ZF, Lian JY, Huang GM, Ye WH, Cao HL, Wang ZM (2012) Genetic groups in the common plant species Castanopsis chinensis and their associations with topographic habitats. Oikos, 121, 12, 2044-2051.

Wang ZF, Lian JY, Ye WH, Cao HL, Zhang QM, Wang ZM (2016) Pollen and seed flow under different predominant winds in wind-pollinated and wind-dispersed species Engelhardia roxburghiana. Tree Genetics \& Genomes, 12, 116.

Watt AS (1947) Pattern and process in the plant communities. Journal of Chemical Ecology, 35, 1-22.

Whitmore TC (1978) Gaps in the forest canopy. In: Tropical Trees as Living Systems (eds Tomlinson PB, Zimmermann MH), pp. 639-655. Cambridge University Press, Cambridge.

Wu ZY (1980) Vegetation of China. Science Press, Beijing. (in Chinese) [吴征镒 (1980) 中国植被. 科学出版社, 北京.]

Xia B, Lan T, He SA, Deng F, Yao G (1996) Canopy gaps in subalpine spruce-fir forests of the hills around Bitahai Lake, Yunnan Province. Journal of Plant Resources and Environ- 
ment, 5(4), 1-8. (in Chinese with English abstract) [夏冰, 兰涛, 贺善安, 邓飞, 姚淦 (1996) 云南亚高山云冷杉林 林窗的研究. 植物资源与环境, 5(4), 1-8.]

Xie YB, Ma ZP, Yang QS, Fang XF, Zhang ZG, Yan ER, Wang XH (2012) Coexistence mechanisms of evergreen and deciduous trees based on topographic factors in Tiantong region, Zhejiang Province, eastern China. Biodiversity Science, 20, 159-167. (in Chinese with English abstract) [谢玉 涁, 马遵平, 杨庆松, 方晓峰, 张志国, 阎恩荣, 王希华 (2012) 基于地形因子的天童地区常绿树种和落叶树种共 存机制研究. 生物多样性, 20, 159-167.]

Yamamoto S (1992) Gap characteristics and gap regeneration in primary evergreen broad-leaved forest of western Japan. Botanical Magazine, 105, 29-45.

Yan SJ, Hong W, Wu CZ (2004) Gaps and their natural disturbance characteristics in mid-subtropical evergreen broadleaved forest in Wanmulin. Chinese Journal of Applied Ecology, 15, 1126-1130. (in Chinese with English abstract) [阊淑君, 洪伟, 吴承祯 (2004) 福建万木林中亚 热带常绿榈叶林林隙更新研究. 应用生态学报, 15, 11261130.]

Yang QS, Ma ZP, Xie XB, Zhang ZG, Wang ZH, Liu HM, Li P, Zhang N, Wang DL, Yang HB, Fang XF, Yan ER, Wang $\mathrm{XH}$ (2011) Community structure and species composition of an evergreen broad leaved forest in Tiantong's 20 ha dynamic plot, Zhejiang Province, eastern China. Biodiversity Science, 19, 215-223. (in Chinese with English abstract) [杨 庆松, 马遵平, 谢玉彬, 张志国, 王樟华, 刘何铭, 李萍, 张娜, 王达力, 杨海波, 方晓峰, 阎恩荣, 王希华 (2011) 浙江天童20 ha常绿阔叶林动态监测样地的群落特征. 生 物多样性, 19, 215-223.

Ye WH, Cao HL, Huang ZL, Lian JY, Wang ZG, Li L, Wei SG, Wang ZM (2008) Community structure of a $20 \mathrm{hm}^{2}$ lower subtropical evergreen broadleaved forest plot in Dinghushan, China. Journal of Plant Ecology (Chinese Ver- sion), 32, 274-286. (in Chinese with English abstract) [叶万 辉, 曹洪麟, 黄忠良, 练琚愉, 王志高, 李林, 魏识广, 王 章明 (2008) 鼎湖山南亚热带常绿阔叶林20公顷样地群 落特征研究. 植物生态学报, 32, 274-286.]

Zang RG (1998) Research advance of canopy gap dynamics. Chinese Journal of Ecology, 17, 50-58. (in Chinese with English abstract) [臓润国 (1998) 林窗动力学研究进展. 生态学杂志, 17, 50-58.]

Zang RG, Yu SX, Liu JY, Yang YC (1999) The gap phase regeneration in a tropical montane rain forest in Bawangling, Hainan Island. Acta Ecologica Sinica, 19, 151-158. (in Chinese with English abstract) [㶓润国, 余世孝, 刘静 艳, 杨彦承 (1999) 海南霸王岭热带山地雨林林隙更新规 律的研究. 生态学报, 19, 151-158.]

Zhang J, Hu JB, Lian JY, Fan ZJ, Ouyang XJ, Ye WH (2016) Seeing the forest from drones: testing the potential of lightweight drones as a tool for long-term forest monitoring. Biological Conservation, 198, 60-69.

Zhang ZG, Ma ZP, Liu HM, Zheng ZM, Xie YB, Fang XF, Wang XH (2013) Topographic distribution patterns of forest gap within an evergreen broad-leaved forest in Tiantong region of Zhejiang Province, Eastern China. Chinese Journal of Applied Ecology, 24, 621-625. (in Chinese with English abstract) [张志国, 马遵平, 刘何铭, 郑泽梅, 谢玉涁, 方 晓峰, 王希华 (2013) 天童常绿阔叶林林窗的地形分布 格局. 应用生态学报, 24, 621-625. ]

Zhu JJ, Kang HZ, Hu LL (2005) Estimation on optical porosity or canopy closure for a forest stand with hemispherical images. Chinese Journal of Ecology, 24, 1234-1240. (in Chinese with English abstract) [朱教君, 康宏樟, 胡理乐 (2005) 应用全天空照片估计林分透光孔隙度(郁闭度). 生态学杂志, 24, 1234-1240.]

(责任编委: 藏润国 责任编辑: 黄祥忠) 